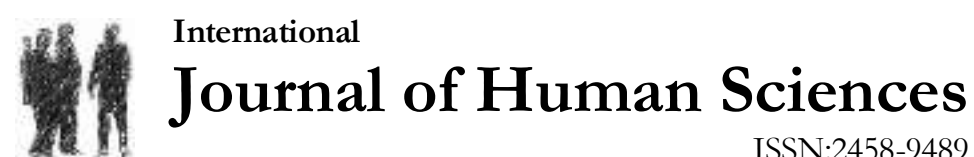

Volume 14 Issue 4 Year: 2017

\section{The investigation of the depression levels of parents of children with autism ${ }^{1}$}

\author{
Mensure Aydin ${ }^{2}$ \\ Ahmet Gokbayrak ${ }^{3}$ \\ Muhammet Eyup Uzuner ${ }^{4}$ \\ Hakan Akdeniz ${ }^{5}$ \\ Bergun Meric Bingul ${ }^{6}$
}

\begin{abstract}
The aim of this study was to investigate the depression levels of parents of children with autism. The depression levels of mothers $(\mathrm{N}=35)$ and fathers $(\mathrm{N}=23)$ of autistic children educated in special education and rehabilitation centers were examined. In this study, socio-demographic features i.e., gender, age, education of mothers and fathers, occupation, were collected and the Beck Depression Inventory was applied to the parents to determine the risk factors of depression, symptom levels. The inventory includes 21 phrases of self-evaluation and possible scores range from 0 - 63. In the statistical analysis of the data, frequency values were applied to the evaluation of the demographic status. The mean and standard deviation were determined to evaluate the depression levels. T-tests were performed to compare the depression levels of mothers and fathers. An Anova test was performed to assess the relationships between the parameters. As a result, it was determined that mothers of autistic children have medium levels of depression $(18,80 \pm 11,05)$, and fathers of autistic children have mild levels of depression. T-test analysis showed no significant differences between depression levels of mothers and fathers $(p<0,05)$. Additionally; when income rates, occupations and educational status parameters were taken into account there was no significant difference according to the Anova test $(p<0,05)$. In conclusion, mothers of autistic children have higher depression levels than the fathers.
\end{abstract}

Keywords: Autism; depression; family with autism.

\section{Introduction}

After becoming aware of a pregnancy, the expectations and desires of the parents and the entire family and is to have a healthy child. However, when a child is born with a disability, it creates frustration, stress and mental trauma for the parents and other members of the family (Kaytez et al., 2015; AltugOzsoy, 2006).

\footnotetext{
${ }^{1}$ Orally presented in 3 rd International CONFERENCE on LIFELONG LEARNING AND LEADERSHIP FOR ALL, Porto PORTUGAL, 13/09/2017.

${ }^{2}$ Assoc. Prof., Kocaeli University, Faculty of Sports Sciences, Recreation Department, mensure@kocaeli.edu.tr

${ }^{3}$ MSc., Kocaeli University, Faculty of Sports Sciences, Sports Management, agokbayrak@gmail.com

4PhD.,Ress. Asst., Kocaeli University, Faculty of Sports Sciences, meu1985@,hotmail.com

5PhD., Kocaeli University, Faculty of Sports Sciences, Recreation Department, hakdeniz@,hotmail.com

${ }^{6}$ Assoc. Prof., Kocaeli University, Faculty of Sports Sciences, Trainer Education Department, bergunmeric@gmail.com
} 
Aydin, M., Gokbayrak, A., Uzuner, M. E., Akdeniz, H., \& Bingul, B. M. (2017). The investigation of the depression levels of parents of children with autism. Journal of Human Sciences, 14(4), 4694-4700. doi:10.14687/jhs.v14i4.5090

Some of the most common special needs children are autistic children. Autism is, in the broadest sense, a neuropsychiatric disorder, which cannot be determined precisely, and affects the life of the child and the family in a negative way, because of the abnormalities of social relations, communication, behavior and delayed cognitive development (Yanardag et al., 2009; Arslan\&Ince, 2015; Ustuner Top, 2009; Gulec-Aslan et al., 2009). Autism or autistic disorder is only one of the categories that define developmental disability under the name of "Autistic Spectrum Disorders" or "Pervasive Developmental Disorders".

Children with autistic spectrum disorder are a mental health challenge for parents. For families, autistic children may cause more stress and depression than other physically disabled and chronic ill children (Ingersoll \&Hambrick, 2011) and parents may feel concerned about the impact of their autistic children on their other children or how they will affect their own lives. There are often difficulties for the child with specific needs to adapt to the family life. The basis of all these concerns often are families' fears of being ignorant of the unknown (Ustuner Top, 2009).

Autistic characteristics differ from child to child. Parents are often confronted with a series of behaviors that are difficult to define. Stresses on families are caused by dealing with the needs and wishes of a child who cannot communicate, trying to keep up with family commitments, coping with different forms of behavior in children and protecting them from danger. The reactions parents may experience in these traumatic situations include feelings of guilt, difficulties finding extra time and energy for their children and heavy financial burdens for education and health expenditures, which, because of the increased anxiety and stress, can lead to depression (Firat, 2016; Girli, 2006; Ustuner Top, 2009). On top of this, families often believe that they are not strong enough to deal with the responsibilities which is another source of depression (Kaytez et al., 2015; Ergin et al., 2007). Depression usually occurs after a process of suffering.

The aim of this study was to examine the depression levels of families with autistic children.

\section{Method}

The research was of a qualitative type and depression levels of mothers $(35 \pm 18,80)$ and fathers $(23 \pm 13,13)$ of autistic children who attended special education and rehabilitation institutions were investigated.

Socio-demographic characteristics (sex, age, mother's education, father's education, occupation) of the families with autistic children were ascertained with one-on-one interviews. The Beck Depression Inventory (1961) includes 21 phrases of self-evaluation and the scale was used to measure the level and severity of depression in the interviewed families. The range of the possible scores was between $0-63$. The validity and reliability of the Turkish version of the form was conducted by Hisli (1989) (Ayvaz et al., 2006).

The families were informed about the study and verbal consent was obtained. The interviews were conducted at the appropriate times in autistic rehabilitation centers. In the statistical analysis of the data, frequency values were applied to the evaluation of the demographic status and the mean and standard deviation were calculated to evaluate the depression levels. T-tests were performed to compare the depression levels of mothers and fathers. An Anova test was performed to assess the relationships between the parameters. 
Aydin, M., Gokbayrak, A., Uzuner, M. E., Akdeniz, H., \& Bingul, B. M. (2017). The investigation of the depression levels of parents of children with autism. Journal of Human Sciences, 14(4), 4694-4700. doi:10.14687/jhs.v14i4.5090

\section{Findings}

Table 1.Distribution of the parents

\begin{tabular}{ccc}
\hline Variable & $\mathrm{n}$ & $\%$ \\
\hline Mother & 35 & 60,3 \\
Father & 23 & 39,7 \\
Total & 58 & 100,0 \\
\hline
\end{tabular}

58 participants participated in this study (Mothers \%60,3, fathers \%39,7).

Table 2.Distribution of the ages

\begin{tabular}{ccc}
\hline Variables & $\mathrm{n}$ & $\%$ \\
\hline $25-35$ age & 23 & 39,7 \\
3645 ages & 27 & 46,6 \\
$46-55$ age & 8 & 13,8 \\
Total & 58 & 100,0 \\
\hline
\end{tabular}

Average ages of the participants; $\% 39,7$ were at the age of $25-35, \% 46,6$ were at the age of $36-45$, $\% 13,8$ were at the age of $46-55$.

Table 3.Educational levels of the mothers

\begin{tabular}{ccc}
\hline Variable & $\mathrm{n}$ & $\%$ \\
\hline High School & 16 & 27,6 \\
Associate's Degree & 12 & 20,7 \\
Bachelor's Degree & 28 & 48,3 \\
Master's Degree & 2 & 3,4 \\
Total & 58 & 100,0 \\
\hline
\end{tabular}

Educational levels of the mothers were \%48,3 Bachelor's degree, \%27,6 High School, \%20,7 Associate's degree, \%3,4 Master's Degree.

Table 4.Educational levels of the fathers

\begin{tabular}{ccc}
\hline Variable & $\mathrm{n}$ & $\%$ \\
\hline High School & 7 & 12,1 \\
Associate's Degree & 9 & 15,5 \\
Bachelor's Degree & 41 & 70,7 \\
Master's Degree & 1 & 1,7 \\
Total & 58 & 100,0 \\
\hline
\end{tabular}

Educational levels of the fathers were; \%70,7 Bachelor's Degree, \%15,5 Associate's Degree, $\% 12,1$ 'i High School, \%1,7 Master's Degree. 
Aydin, M., Gokbayrak, A., Uzuner, M. E., Akdeniz, H., \& Bingul, B. M. (2017). The investigation of the depression levels of parents of children with autism. Journal of Human Sciences, 14(4), 4694-4700. doi:10.14687/jhs.v14i4.5090

Tablo 5.Occupational distribution of the parents

\begin{tabular}{ccc}
\hline Variable & $\mathrm{n}$ & $\%$ \\
\hline House wife & 14 & 24,1 \\
Employee & 4 & 6,9 \\
Self-employment & 22 & 37,9 \\
Civil Servant & 18 & 31,0 \\
Total & 58 & 100,0 \\
\hline
\end{tabular}

Occupational distribution of the parents were; \%37,9 Self-employment, \%31 Civil Servant, \%24,1 House wife, $\% 6,9$ employee.

Table 6.T test results of the depression levels of the parents

\begin{tabular}{ccccccc}
\hline & Sex & $\mathrm{N}$ & Min. & $\begin{array}{c}\text { Std. } \\
\text { Deviation }\end{array}$ & $\mathrm{t}$ & $\mathrm{p}$ \\
\hline $\begin{array}{c}\text { Depression Total } \\
\text { Points }\end{array}$ & Mother & 35 & 18,8 & 11,05 & 1,222 & \multirow{2}{*}{060} \\
\hline $\mathrm{P}<0,05$ & Father & 23 & 13,13 & 10,88 & 1,922 & \\
\hline
\end{tabular}

There was no significant difference in the depression parameters of the parents that participated in the study $(\mathrm{p}>0,05)$. Depression levels; mothers $(18,80 \pm 11,05)$ moderate, fathers $(13,13 \pm 10,88)$ mild depression.

Table 7.Anova test results according to the occupational variables

\begin{tabular}{ccccc}
\hline Variables & $\mathrm{n}$ & $\%$ & $\mathrm{t}$ & $\mathrm{p}$ \\
\hline House wife & 14 & 19,92 & & \\
Employee & 4 & 10,75 & & \\
Self-employment & 22 & 12,5 & 2,538 &, 066 \\
Civil Servant & 18 & 20,16 & & \\
Total & 58 & 16,55 & & \\
\hline
\end{tabular}

In the ANOVA test result of the subjects according to occupational variables; house wives $(19.92 \pm 12,36)$ moderate depression, employees (10.75 \pm 6.23$)$ mild level, self-employments (12.50 \pm 10.11$)$ mild level, civil servants $(20.16 \pm 11.02)$ moderate depression levels were observed. Generally, the mean depression levels of all groups were mild level of depression (16.55 $\pm 11,24)$.

Table 8.Anova test result of the educational levels of the mothers

\begin{tabular}{cccccc}
\hline Variables & $\mathrm{n}$ & Mean & $\begin{array}{c}\text { Std. } \\
\text { Deviation }\end{array}$ & $\mathrm{f}$ & $\mathrm{p}$ \\
\hline $\begin{array}{c}\text { High School } \\
\text { Associate's } \\
\text { Degree }\end{array}$ & 16 & 17,56 & 10,19 & & \\
$\begin{array}{c}\text { Bachelor's } \\
\text { Degree }\end{array}$ & 28 & 17,66 & 11,69 & & \\
$\begin{array}{c}\text { Master's } \\
\text { Degree }\end{array}$ & 2 & 12 &, 00 & & \\
Total & 58 & 16,55 & 11,24 & & \\
\hline
\end{tabular}


Aydin, M., Gokbayrak, A., Uzuner, M. E., Akdeniz, H., \& Bingul, B. M. (2017). The investigation of the depression levels of parents of children with autism. Journal of Human Sciences, 14(4), 4694-4700. doi:10.14687/jhs.v14i4.5090

There was no significant difference in the comparison of the educational variables and Beck Depression scale total scores of the mothers who participated in this research $(p>0,05)$. In the ANOVA test result of the mothers according to the educational variables; High school $(17,56 \pm 10,19)$ moderate depression, associate's degree $(13,66 \pm 11,69)$ mild depression, bachelor's degree $(17,53 \pm 12,10)$ moderate depression, master's degree $(12 \pm 0)$ mild depression levels were observed.

Table 9. Anova test result of the educational levels of the fathers

\begin{tabular}{cccccc}
\hline Variables & $\mathrm{n}$ & Mean & $\begin{array}{c}\text { Std. } \\
\text { Deviation }\end{array}$ & $\mathrm{f}$ & $\mathrm{p}$ \\
\hline $\begin{array}{c}\text { High School } \\
\text { Associate's } \\
\text { Degree }\end{array}$ & 7 & 11,4286 & 7,41299 & & \\
$\begin{array}{c}\text { Bachelor's } \\
\text { Degree }\end{array}$ & 41 & 16,9512 & 12,58561 &, 714 &, 548 \\
$\begin{array}{c}\text { Master's } \\
\text { Degree } \\
\text { Total }\end{array}$ & 1 & 12,0000 &, 00 & & \\
\hline
\end{tabular}

There was no significant difference in the comparison of the educational variables and Beck Depression scale total scores of the fathers who participated in this research $(p>0,05)$. In the ANOVA test result of the fathers according to the educational variables; High School $(11,42 \pm 7,41)$ mild depression, Associate's Degree $(19,22 \pm 5,78)$ moderate depression, Bachelor's Degree $(16,95 \pm 12,58)$ moderate depression, Master's Degree (12 \pm 0$)$ mild depression were observed.

\section{Results, Conclusions and Recommendations}

In assessing the problems and mental conditions of families with autistic children, qualitative research identified that parents are forced to accept the situation when their children are diagnosed with autism, they undergo drastic changes in their lifestyles, become isolated from their communities, more sensuality, they worry about their future, and give up many things that wanted to do. Despite all of this, they often come to find that taking care of their children gives them happiness and initiate major changes in the ways they view life (Ustuner Top, 2009).

In a similar study; variables of families participating in the research were as follows: $80 \%$ were mothers, $54 \%$ were in the 36-50 age group, $62 \%$ were unemployed, $28 \%$ graduated from high school, $66 \%$ equal income \& expense, $58 \%$ had 2 children, $92 \%$ were not relative, $36 \%$ had disabled children within the 6-9 age group, $74 \%$ of the children were mentally disabled, $56 \%$ of the children were male, $44 \%$ were female, $68 \%$ of them were educated in special education (DereliveOkur, 2008). In this study, occupational groups of the parents included: $24,1 \%$ were housewives, $6,9 \%$ were employees, $37,9 \%$ were self-employed and $31 \%$ were civil servants. Making up the participants were $60.3 \%$ mothers, $39,7 \%$ fathers, with average ages as follows: 25-35 (39,7\%), 36-45 (46,6\%), and 46-55 (13,8\%). Educational levels of mothers were: $27,6 \%$ high school, $20,7 \%$ associate degree, $52.13 \%$ bachelor's degree. Educational levels of the fathers were; $12,1 \%$ high school, 15,5\% associate degree, and 72,4\% bachelor's degree.

In a study of the depression levels of parents with a disabled child, (Softa, 2013), the parents' mean depression scores were moderate: $21,600 \pm 10,722$. In a similar study in which the depression levels of disabled families were investigated, families were reported as severely depressed: $39,98 \pm 10,71$ 
Aydin, M., Gokbayrak, A., Uzuner, M. E., Akdeniz, H., \& Bingul, B. M. (2017). The investigation of the depression levels of parents of children with autism. Journal of Human Sciences, 14(4), 4694-4700. doi:10.14687/jhs.v14i4.5090

(Dereli\&Okur, 2008). Ingersoll veHambrick (2011) found depression levels of families with autistic children were moderate $21.42 \pm 12.85$. In research that focused on the depression levels of both families with healthy children and families with autistic children, results showed that the depression levels of families with autistic children were higher (Durakan et al., 2010; Towairqi et al., 2015; Kiani et al., 2014).

As a result of studies on the level of depression and determination of the factors affecting parents with disabled children, parents' total depression score average was found to be low: $13.44 \pm 9.51$ (Erginetal., 2007). According to the Beck Anxiety Scale, scores used in a study to determine anxiety, depression and stress levels of mothers of both mentally and physically disabled children, showed that mothers had higher depression scores than the control group (Uguz et al., 2004).

Demir et al. (2012) investigated depression levels of mothers of mentally disabled children, and the average scores were: 21.60 12.99 . In their work, Olsson \& Hwang (2001) found that autistic families reported higher depression scores than the control group (normal developmental child) and children with mental retardation. In our study, the depression levels of mothers (18.80 \pm 11.05$)$ and fathers $(13.13 \pm 10.88)$ with autistic children were found to support the literature.

In a study that investigated the attitudes of mothers with mentally disabled children toward coping with depression, anxiety and stress (Sengul\&Bayhan, 2013), the mean score using the Hamilton Depression Rating Scale was 6.0, the lowest and highest scores were 1-23, the mean score of the control group was 4.5, the lowest and highest scores were 0-19. The difference between these two groups is statistically significant. For depression levels, it was determined as severe depression $(39,98 \pm 10,71)$, and mothers $(41.4 \pm 10.38)$ were found to have higher depression score than the fathers (34.3 \pm 10.60$)$ (Dereli\&Okur, 2008).

In a study of depression and anxiety levels of parents of autistic children, mothers were found to have higher depression scores than fathers (Firat, 2016). In our study, similar results were obtained for the depression levels of mothers $(18.80 \pm 11,05)$ and fathers $(13,13 \pm 10,88)$.

According to the results of our study and comparisons with other research, we concluded that parents of autistic children have higher levels of depression. The depression scores of the mothers were found to be higher than the depression scores of the fathers.

\section{References}

Al Towairqi, W., Alosaimi, W., Al Zaidi, S., Helmy, F. F., \& Al Sherif, E. (2017).Depression among mothers of autistic spectral disorder children. International Journal of Contemporary Pediatrics, 2(2), 119-126.

AltugOzsoy, S. (2006). Examination of the difficulties of families with children with mental retardation, Family and Community, 3(9):69.

Arslan, E., \&Ince, G. (2015).The Effects of 12 weeks Exercise Program on the Level of Gross Motor Skill of the Children with Atypical Autism. International Journal of Sports, Exercise and Training Science, 1(1),

Ayvaz, S., Hocaoglu, C..,Tiryaki, A., \&Ak, I. (2006). Postpartum depression in Trabzon province center and associated demographic risk factors in pregnancy. Journal of Turkish Psychiatry, 17(4), 243-251.

Demir, G., Ozcan, A., Kizilirmak, A. (2010), Determination of the Depression Levels of Disabled Children's Mothers. Journal of Anatolia Nursing and Health Sciences, 13(4). 
Aydin, M., Gokbayrak, A., Uzuner, M. E., Akdeniz, H., \& Bingul, B. M. (2017). The investigation of the depression levels of parents of children with autism. Journal of Human Sciences, 14(4), 4694-4700. doi:10.14687/jhs.v14i4.5090

Dereli, F., Okur, S. (2008), Determination of depression status of the families with disabled children, Journal of New Medicine; 25: 164-168.

Durukan, I., Erdem, M., Tufan, A., \&Turkbay, T. (2010). Attitudes of the Mothers of Children with Autistic Spectrum Disorders Towards Coping and Relation to Depression and Anxiety Levels. Journal of Child and Youth Mental Health, 17(2), 75-82.

Ergin, D., Sen, N., Eryilmaz, N. E., Pekuslu, S., \&Kayaci, M. (2007). Determination of depression level and affecting factors of parents with disabled children. Journal of Anatolia Nursing and Health Sciences, 10(1).

Firat, F. (2016). Depression and anxiety levels of parents of autistic children, Cukurova Medical Journal;41(3):539-547.

Ingersoll, B., \&Hambrick, D. Z. (2011).The relationship between the broader autism phenotype, child severity, and stress and depression in parents of children with autism spectrum disorders. Research in Autism Spectrum Disorders, 5(1), 337-344.

Softa, H. K. (2013). Examination of depression levels of parents with disabled children. Journal of Kastamonu Education, 21(2).

Kaytez, N., Durualp, E., \&Kadan, G. (2015). Examination the needs and stress levels of families with disabled children. Journal of Research in Education and Teaching, 4(1).

Kiani, F., Khodabakhsh, M. R., Hashijin, H. K. (2014). Comparison of Parenting- Related Stress and Depression Symptoms in Mothers of Children with and without Autism Spectrum Disorders (ASD), International Journal of Pediatrics (Supplement 5), Vol.2, N.3-3, Serial No.9.

Olsson, M. B., \& Hwang, C. P. (2001).Depression in mothers and fathers of children with intellectual disability. Journal of intellectual disability research, 45(6), 535-543.

Sengul, S., \&Baykan, H. (2013).Attitudes of mothers of mentally retarded children to cope with depression, anxiety, and stress. Journal of Kocatepe Medicine, 14(1).

Uguz, S., Toros, F., Inanc, B. Y., \&Colakkadioglu, O. (2004). Determination of anxiety, depression and stress levels of mothers of mentally and/or physically handicapped children. Clinical Psychiatry, 7(1), 42-7.

Ustuner Top, F. (2009). Assessment of the Problems and Mental Status of the Autistic Child's Families: Qualitative Research. Journal of Child, 9(1):34-42.

Yanardag, M., Yilmaz, I. (2012). An intervention approach in children with autistic disorder: inwater activities. International Journal of Early Childhood Special Education, 4(1), 32-45. 